\title{
Influence of preoperative serum creatinine level and intraoperative volume of contrast medium on the risk of acute kidney injury after transfemoral transcatheter aortic valve implantation: a retrospective observational study
}

Daisuke Miura ${ }^{* *} \mathbb{D}$, Yasutaka Yamada' ${ }^{1}$ Shinichiro Kusaba ${ }^{1}$, Eijiro Nogami² ${ }^{2}$ Junji Yunoki ${ }^{2}$, Yoshiko Sakamoto ${ }^{3}$, Yutaka Hikichi ${ }^{3}$, Koichi Node ${ }^{3}$ and Yoshiro Sakaguchi ${ }^{1}$

\begin{abstract}
Objective: This study aimed to determine if contrast medium volume (CMV) is a risk factor for acute kidney injury (AKI) during transcatheter aortic valve implantation (TAVI) via a transfemoral approach performed without major complications. All TAVI procedures performed at our institution between March 2014 and March 2018 were retrospectively reviewed. AKI was diagnosed using the Acute Kidney Injury Network classification based on the Valve Academic Research Consortium-2 definition. Procedures performed via a transapical approach and those in which circulatory dynamics failed intraoperatively were excluded.

Results: Eighty-one (96.4\%) of 100 patients scheduled for TAVI were enrolled; seven (8.6\%) developed AKI and 74 $(91.4 \%)$ did not. The serum creatinine $(\mathrm{SC} r)$ level was significantly higher $(\mathrm{p}<0.05)$ and the estimated glomerular filtration rate was significantly lower in the AKI group $(p<0.05)$. The CMV was significantly higher in the AKI group (103 $\mathrm{ml}$ vs $84 \mathrm{ml}, \mathrm{p}<0.05$ ), as was the CMV $\times \mathrm{SCr} / \mathrm{BW}$ value (3.34 vs 1.49, $\mathrm{p}<0.01$ ). The area under the curve for $\mathrm{CMV} \times \mathrm{SCr} / \mathrm{BW}$ was 0.9228 and the cut-off value was 2.99. The CMV, SCr, and estimated glomerular filtration rate affect the likelihood of AKI after transfemoral TAVI and a CMV $\times \mathrm{SCr} / \mathrm{BW}$ value $>2.99$ accurately predicts AKI.
\end{abstract}

Keywords: Transfemoral transcatheter aortic valve implantation, Acute kidney injury, Serum creatinine, Contrast medium

\section{Introduction}

Acute kidney injury (AKI) occurs in up to $30 \%$ of cases after cardiac surgery [1]. AKI after conventional cardiac surgery or percutaneous coronary intervention is associated with prolonged hospitalisation and increased mortality [2-6]. AKI can be caused by nephrotoxins, hypoxia,

\footnotetext{
*Correspondence: daisuke.m.1217@gmail.com

${ }^{1}$ Department of Anesthesiology, Saga University Medical Hospital, Saga, Japan

Full list of author information is available at the end of the article
}

mechanical trauma, inflammation, cardiopulmonary bypass, and hemodynamic instability, and the risk of its occurrence may be affected by the choice of fluids, vasoactive agents, and transfusion strategy [7]. Contrastinduced nephropathy (CIN) is a type of AKI that occurs after administration of contrast medium and is usually reversible. The pathogenesis of CIN is uncertain but is thought to involve hypoxic injury and generation of free radicals [8]. The contrast medium volume (CMV) is considered to be a major risk factor for AKI [9-14]. Several studies have demonstrated an association between 
a $\mathrm{CMV} \times$ serum creatinine $(\mathrm{SCr}) /$ body weight $(\mathrm{BW})$ value $>5.0$ and an increased risk of AKI or need for dialysis after percutaneous coronary intervention [11-14].

Transcatheter aortic valve implantation (TAVI) is preferred in patients with severe aortic stenosis who are not surgical candidates; however, AKI reportedly occurs in 8.3-58\% of cases [15-21]. Predictors of AKI after TAVI include the baseline creatinine concentration [19, 22, 23], blood transfusion [15, 24], a transapical (TA) approach $[21,25]$, peripheral vascular disease [26], the EuroSCORE (Logistic European System for Cardiac Operative Risk Evaluation) [24], diabetes mellitus [23, 26] and use of a contrast agent [27]. However, the impact of CMV on the risk of AKI after TAVI remains controversial; although most studies have not shown a significant effect $[15,16$, $19,21,28,29]$, there are data suggesting that a higher dose might have a negative impact [30]. There are several explanations for these conflicting findings. First, the definition of AKI in studies of AKI after TAVI lacks standardisation [31] and second, most studies have included the TA approach, which is a known risk factor for AKI after TAVI $[15,17,21,25]$. In this analysis of the influence of renal function-based contrast dosing on the risk of AKI, defined according to the VARC-2 criteria [32], we only included patients in whom transfemoral (TF) TAVI had been performed and who did not have major perioperative complications.

\section{Main text}

\section{Study population}

Patients who underwent transfemoral TAVI for severe aortic valve stenosis at our institution between March 2014 and March 2018 were considered for enrolment. Patients who underwent TA or trans-subclavian TAVI were excluded, as were those who developed major perioperative complications. The study protocol was approved by our institutional review board. The requirement for informed consent was waived.

\section{TAVI procedures}

The procedures were performed in a hybrid operating room under general anaesthesia. Transarterial access was established percutaneously or after surgical cut-down. A self-expanding valve prosthesis (Core-Valve, Medtronic Inc., Minneapolis, MN) or a balloon-expandable prosthesis (Edwards SAPIEN, Edwards Lifesciences, Irvine, CA) was used. Rapid right ventricular pacing was performed during balloon dilation for a native aortic valve and at the time of implantation for a balloon-expandable bioprosthetic valve. The position of the prosthetic valve was decided according to the intraoperative multislice computed tomographic findings. The contrast agent used was Iopamidol, which is iodinated and non-ionic and has low osmolarity. All patients were extubated within $6 \mathrm{~h}$ of the procedure.

\section{Definitions and collection of data}

The data collected included age, sex, height, BW, the presence of hypertension, hyperlipidaemia, diabetes mellitus, peripheral artery disease, cerebrovascular disease, prior percutaneous coronary intervention, prior coronary artery bypass grafting, chronic obstructive pulmonary disease, SCr, estimated glomerular filtration rate (eGFR), or chronic kidney disease (CKD), STS (Society of Thoracic Surgeons Predictive Risk of Mortality) score, and Logistic EuroSCORE. The SCr level was measured on the day before TAVI and on days $0,1,2,3,5$, and 7 thereafter. The $\mathrm{CMV} \times \mathrm{SCr} / \mathrm{BW}$ values were calculated based on the preoperative $\mathrm{SCr}$ and $\mathrm{BW}$ and the intraoperative CMV.

AKI was defined according to the VARC-2 definition as an absolute reduction in kidney function (for $<7$ days) as follows: stage 1, an increase in SCr to 150-199\%, an increase in $\mathrm{SCr}$ of $\geq 0.3 \mathrm{mg} / \mathrm{dl}$, or urine output $<0.5 \mathrm{ml} /$ $\mathrm{kg} / \mathrm{h}$ for $>6 \mathrm{~h}$ but $<12 \mathrm{~h}$; stage 2 , an increase in $\mathrm{SCr}$ to $200-299 \%$ or urine output $<0.5 \mathrm{ml} / \mathrm{kg} / \mathrm{h}$ for $>12 \mathrm{~h}$ but $<24 \mathrm{~h}$; stage 3 , an increase in $\mathrm{SCr}$ to $\geq 300 \%$ or $\mathrm{SCr} \geq 4.0 \mathrm{mg} / \mathrm{dl}$ with an acute increase of $\geq 0.5 \mathrm{mg} / \mathrm{dl}$ or urine output $<0.3 \mathrm{ml} / \mathrm{kg} / \mathrm{h}$ for $\geq 24 \mathrm{~h}$ or anuria for $\geq 12 \mathrm{~h}$. Patients receiving renal replacement therapy are considered to meet the stage 3 criteria. We did not diagnose AKI based on urine volume. The patient demographics, clinical characteristics, and intraoperative findings were compared between the AKI group and the non-AKI group.

\section{Statistical analysis}

We grouped the patients according to whether they developed postoperative AKI and searched for contributing factors. Categorical variables are presented as the frequency and percentage and were compared using the chi-square or Fisher's exact test. The normality of distributions was assessed using the Shapiro-Wilk test; normal and skewed continuous variables are presented as the mean \pm standard deviation and median (interquartile range), respectively. Continuous variables were compared using the Student's $t$-test or Mann-Whitney $U$ test.

Univariate logistic regression analysis was used to test variables for statistically significant differences. Receiveroperating characteristic (ROC) curve analyses were used to examine the ability of the variables to predict AKI. The prediction performance of each variable was examined by comparing the area under the ROC curves. All tests were two-sided. A p-value $<0.05$ was considered statistically significant. All analyses were performed using JMP Pro 13 (SAS Institute Inc., Cary, NC). 


\section{Results}

One hundred patients underwent TAVI during the study period. The TA or transsubclavian approach was used in 16 patients and the TF approach in 84. Three patients who underwent TF-TAVI developed intraoperative complications and were excluded, leaving data for 81 patients available for analysis (see Additional file 1: Figure S1). AKI occurred in 7 (8.6\%) of these patients and was categorised as grade 1 in $6(85.7 \%)$ and grade 3 in one $(14.3 \%)$. No patient required renal replacement therapy. The baseline characteristics of the non-AKI $(n=74)$ and AKI $(n=7)$ groups are shown in Table 1 . The mean age was $84.6 \pm 5.1$ (range, 64-94) years and $72.8 \%$ were women. The mean STS score was $6.9 \% \pm 3.7 \%$ and the mean Logistic EuroSCORE was $18.7 \% \pm 10.9 \%$. There was no significant between-group difference in the frequency of CKD. The preoperative SCr value was significantly higher and the preoperative eGFR was significantly lower in the AKI group than in the non-AKI group $(1.32 \mathrm{mg} /$ $\mathrm{dl}$ vs $0.87 \mathrm{mg} / \mathrm{dl}, \mathrm{p}=0.0232$, and $29.5 \mathrm{ml} / \mathrm{min} / 1.73 \mathrm{~m}^{2}$ vs $49.6 \mathrm{ml} / \mathrm{min} / 1.73 \mathrm{~m}^{2}, \mathrm{p}=0.0395$, respectively).

There was no significant between-group difference in operating time, anaesthesia time, intraoperative infusion volume, blood loss, urine volume, transfusion volume, or use of elective percutaneous cardiopulmonary

Table 1 Baseline characteristics of the study population

\begin{tabular}{|c|c|c|c|}
\hline & Non-AKI $(n=74)$ & $A K I(n=7)$ & p-value \\
\hline Age, years & $85.5(82-88)$ & $83(81-86)$ & 0.337 \\
\hline Male sex & $19(25.7 \%)$ & $3(42.9 \%)$ & 0.382 \\
\hline Height, cm & $147.8 \pm 9.8$ & $150.0 \pm 7.0$ & 0.564 \\
\hline Body weight, kg & $48.2 \pm 10.2$ & $44.3 \pm 9.3$ & 0.323 \\
\hline Hypertension & $59(79.7 \%)$ & $6(85.7 \%)$ & 1.000 \\
\hline Hyperlipidaemia & $41(55.4 \%)$ & $5(71.4 \%)$ & 0.693 \\
\hline Diabetes mellitus & $13(17.6 \%)$ & $2(28.6 \%)$ & 0.608 \\
\hline PAD & $16(21.6 \%)$ & $1(14.3 \%)$ & 1.000 \\
\hline CVD & $18(24.3 \%)$ & $1(14.3 \%)$ & 1.000 \\
\hline COPD & $23(31.1 \%)$ & $3(42.9 \%)$ & 0.675 \\
\hline CABG & $7(9.5 \%)$ & $1(14.3 \%)$ & 0.531 \\
\hline $\mathrm{PCl}$ & $12(16.2 \%)$ & $3(42.9 \%)$ & 0.114 \\
\hline CKD & $57(77.0 \%)$ & $6(85.7 \%)$ & 1.000 \\
\hline $\mathrm{sCr}, \mathrm{mg} / \mathrm{dl}$ & $0.87(0.72-1.15)$ & $1.32(0.84-1.67)$ & 0.023 \\
\hline $\mathrm{eGFR}, \mathrm{mL} / \mathrm{min} / 1.73 \mathrm{~m}^{2}$ & $49.6(37.1-60.0)$ & $29.5(23.2-54.3)$ & 0.039 \\
\hline$E F<40 \%$ & $7(9.5 \%)$ & $1(14.3 \%)$ & 0.531 \\
\hline Euro SCORE, \% & $16.2(12.1-22.8)$ & $17.4(8.4-19.2)$ & 0.556 \\
\hline STS score, \% & $5.7(4.3-7.6)$ & $8.4(6.6-10.6)$ & 0.078 \\
\hline
\end{tabular}

The data are shown as the mean \pm standard deviation, number (percentage), or median (interquartile range) as appropriate

AKI: Acute kidney injury; CABG: coronary artery bypass grafting; CKD: chronic kidney disease; COPD: chronic obstructive pulmonary disease; CVD: cerebrovascular disease; EF: ejection fraction; eGFR: estimated glomerular filtration rate; EuroSCORE: European System for Cardiac Operative Risk Evaluation; PAD: peripheral artery disease; STS: Society of Thoracic Surgery
Table 2 Perioperative findings in the study population

\begin{tabular}{|c|c|c|c|}
\hline & Non-AKI $(n=74)$ & AKI $(n=7)$ & p-value \\
\hline Operating time (min) & $109(97-131)$ & $121(108-229)$ & 0.135 \\
\hline $\begin{array}{l}\text { Anaesthesia time } \\
\text { (min) }\end{array}$ & $242(226-273)$ & $293(240-339)$ & 0.071 \\
\hline $\begin{array}{l}\text { Intraoperative fluids } \\
(\mathrm{ml})\end{array}$ & $1832(1573-2210)$ & 2001 (1612-2312) & 1.000 \\
\hline Bleeding (ml) & $49(30-94)$ & $60(40-100)$ & 0.584 \\
\hline Urine (ml) & 700 (395-1243) & $500(330-800)$ & 0.178 \\
\hline Transfusion (ml) & $280(0-560)$ & $280(280-560)$ & 0.085 \\
\hline $\mathrm{CMV}(\mathrm{ml})$ & $84(75-93)$ & $103(85-121.08)$ & 0.025 \\
\hline $\mathrm{CMV} \times \mathrm{SCr} / \mathrm{BW}$ value & $1.49(1.25-2.21)$ & $3.34(3.00-4.52)$ & 0.0002 \\
\hline $\begin{array}{l}\text { Fluoroscopy time } \\
\text { (min) }\end{array}$ & $30.5(24.7-38.6)$ & $30.7(24.8-89.1)$ & 0.602 \\
\hline PCPS & $7(9.46 \%)$ & $0(0.0 \%)$ & 1.000 \\
\hline
\end{tabular}

The data are shown as the number (percentage) or median (interquartile range) as appropriate

AKI: Acute kidney injury; BW: body weight; CMV: contrast medium volume; PCPS: percutaneous cardiopulmonary support; $\mathrm{SCr}$ : serum creatinine

support (Table 2). The CMV was significantly higher in the AKI group than in the non-AKI group (103 $\mathrm{ml}$ vs $84 \mathrm{ml}, \mathrm{p}=0.025)$, as was the $\mathrm{CMV} \times \mathrm{SCr} / \mathrm{BW}$ value $(3.34$ vs $1.49, \mathrm{p}=0.0002)$.

The SCr, eGFR, CMV, and CMV $\times \mathrm{SCr} / \mathrm{BW}$ value were included in the logistic regression analysis. The area under the ROC curve (see Additional file 2: Figure S2) showed that the $\mathrm{CMV} \times \mathrm{SCr} / \mathrm{BW}$ value was best able to predict AKI, with an area under the curve of 0.9228 (95\% confidence interval $0.650-0.984$ ), a cut-off of 2.99 , a sensitivity of $85.7 \%$, and a specificity of $90.4 \%$. The area under the curve for the $\mathrm{CMV} \times \mathrm{SCr} / \mathrm{BW}$ value was significantly higher than that for the other variables (Table 3 ).

\section{Discussion}

In this study, 7 patients (8.6\%) undergoing TF-TAVI for severe aortic stenosis developed AKI; 6 (7.4\%) had stage 1 AKI and one (1.2\%) had stage 3 AKI according to the VARC-2 criteria. No patient needed renal replacement therapy. Risk factors for AKI included the $\mathrm{SCr}$, eGFR, $\mathrm{CMV}$, and $\mathrm{CMV} \times \mathrm{SCr} / \mathrm{BW}$ value. $\mathrm{A} \mathrm{CMV} \times \mathrm{SCr} / \mathrm{BW}$

Table 3 Comparison of areas under the curve

\begin{tabular}{lll}
\hline & AUC (95\% Cl) & p-value \\
\hline CMV $\times$ SCr/BW value & $0.9228(0.6757-0.9856)$ & Reference \\
CMV & $0.7683(0.5095-0.9137)$ & 0.0345 \\
SCr & $0.7606(0.5205-0.9029)$ & 0.0230 \\
eGFR & $0.7375(0.4383-0.9100)$ & 0.0193
\end{tabular}

AUC: Area under the curve; BW: body weight; Cl: confidence interval; CMV: contrast medium volume; eGFR: estimated glomerular filtration rate; $\mathrm{SCr}$ : serum creatinine 
value $>2.99$ could be considered the threshold value for prediction of AKI during TF-TAVI and for intervention.

In 2012, the endpoint definitions in the VARC-2 consensus document were revised [31] to include a recommendation for the Acute Kidney Injury Network criteria to add urine output in the definition of AKI and the timing for diagnosis of postoperative AKI was extended from $72 \mathrm{~h}$ to 7 days. A recent meta-analysis identified New York Heart Association functional class IV, previous CKD, requirement for red blood cell transfusion, previous peripheral artery disease, and a TA approach as strong risk factors for AKI after TAVI according to the VARC-2 definition [33]. Furthermore, the rate of AKI was higher in patients who underwent TA-TAVI than in those who underwent TF-TAVI, as reported previously [21, 34-37]. Another study identified major bleeding to be an important risk factor for AKI and to have a significant impact on outcomes [38].

Our rate of AKI following TAVI is consistent with the observations of Keles et al. [39] and Konigstein et al. [28], who found rates of $7.1 \%$ and $16.7 \%$ in 70 and 300 patients, respectively. The definition of AKI used (VARC-2 criteria) and the ratio of TF procedures (92.9\% and 98\%, respectively) in those studies were very similar to those in our study. Consistent with the previous research, we found that the baseline SCr, eGFR, CMV, and $\mathrm{CMV} \times \mathrm{SCr} / \mathrm{BW}$ value predicted AKI. Elhmidi et al. [18] and Seiffert et al. [40] identified a correlation between baseline renal function and incidence of AKI after TAVI. Furthermore, Van Linden et al. [27] reported administration of a greater amount of contrast medium to be an independent risk factor for AKI, while Yamamoto et al. [41] identified a relationship between an increment in the dose of contrast medium and an increased prevalence of AKI in their series of 415 consecutive patients who underwent TF-TAVI.

The $\mathrm{CMV} \times \mathrm{SCr} / \mathrm{BW}$ value has been established as a criterion for prevention of $\mathrm{CIN}$, and a value $>5.0$ was shown to predict post-procedural AKI after percutaneous coronary intervention [11-14]. In our study, a $\mathrm{CMV} \times \mathrm{SCr} / \mathrm{BW}$ value $>2.99$ was a risk factor for $\mathrm{AKI}$ after TAVI. The reason why our threshold $\mathrm{CMV} \times \mathrm{SCr} /$ $\mathrm{BW}$ value was smaller than in an earlier coronary angiography study [11] may lie in the difference in the diagnostic criteria used for AKI and CIN. The diagnostic criterion for CIN is an increase in $\mathrm{SCr}$ of $>0.5 \mathrm{mg} / \mathrm{dl}$ or an increase of $>25 \%$ from baseline in the $48-72 \mathrm{~h}$ following administration of contrast medium [36]. However, the definition of AKI in the VARC-2 document is based on the Acute Kidney Injury Network classification, i.e., only a slight increase in $\mathrm{SCr}$ of $0.3 \mathrm{mg} / \mathrm{dl}$ is needed to diagnose the onset of AKI in patients with normal renal function.
In this study, we excluded patients who underwent TATAVI and those who had massive bleeding or failure of circulatory dynamics intraoperatively. For the first time, it was possible to identify CMV as a risk factor for AKI after TAVI. Furthermore, although the CMV used was smaller than that in previous studies, the incidence of AKI was comparable. Therefore, renal function and body weight should be taken into account when determining the CMV in, for example, an elderly patient with a small body habitus, which is common in Asian populations. By using the $\mathrm{CMV} \times \mathrm{SCr} / \mathrm{BW}$ formula, it is possible to determine the maximum amount of contrast medium that can be used on a case-by-case basis according to preoperative renal function and BW. By determining the maximum dose of the contrast agent, the risk of AKI can be decreased by limiting the CMV, the dilution factor, and the type of contrast agent used. Our findings suggest that avoidance of major complications and reducing the CMV decreases the risk of AKI after TF-TAVI.

\section{Limitations}

This study has several limitations. First, it was small and had a retrospective observational design, so our results may have been affected by unknown cofounders. Second, we did not apply diagnostic criteria based on urine output. Therefore, it is possible that the number of cases of AKI was underestimated. Third, the long-term renal function and outcomes in patients with AKI were not investigated. In a previous study, even a small increase in the baseline creatinine level after TAVI was associated with a worse outcome [25]. The poor prognosis in our patients should encourage better patient selection and management for prevention of AKI.

\section{Additional files}

Additional file 1: Figure S1. Flow chart showing patient selection. TA Transapical; TAVI: transcatheter aortic valve implantation; TF: transfemoral; TS: transsubclavian.

Additional file 2: Figure S2. Receiver-operating characteristic curves for predicting acute kidney injury after transfemoral transcatheter aortic valve implantation. AUC: Area under the curve; BW: body weight; CMV: contrast medium volume; Cre: creatinine; eGFR: estimated glomerular filtration rate; SCr: serum creatinine.

\section{Abbreviations}

AKI: acute kidney injury; AUC: area under the curve; BW: body weight; CIN: contrast-induced nephropathy; CKD: chronic kidney disease; CMV: contrast medium volume; eGFR: estimated glomerular filtration rate; EuroSCORE: Logistic European System for Cardiac Operative Risk Evaluation; ROC: receiver-operating characteristic; SCr: serum creatinine; STS: Society of Thoracic Surgeons Predictive Risk of Mortality; TA: transapical; TAVI: transcatheter aortic valve implantation; TF: transfemoral; VARC: Valve Academic Research Consortium. 


\section{Acknowledgements}

The authors thank the staff of the TAVI team at our institution for their excellent support.

\section{Authors' contributions}

DM conceived of the study and participated in its design, coordination, conduct, analysis, and drafted the manuscript. YY, SK, EN, YS1, JY, and YH participated in the design of the study, conduct, and the interpretation of results. $\mathrm{KN}$ reviewed and edited the manuscript. YS2 participated in the conception and design of the study and secured funding. All authors revised the manuscript for content. All authors read and approved the final manuscript.

\section{Funding}

This study was not supported by any funding.

\section{Availability of data and materials}

The datasets generated during and/or analysed during the current study are available from the corresponding author on reasonable request.

\section{Ethics approval and consent to participate}

The Institutional Research Review Board for Clinical Investigations of Saga University Medical Hospital approved this study (2018-03-09) and waived the requirement for informed consent.

\section{Consent for publication}

Not applicable.

\section{Competing interests}

The authors declare that they have no competing interests.

\section{Author details}

${ }^{1}$ Department of Anesthesiology, Saga University Medical Hospital, Saga, Japan. ${ }^{2}$ Department of Thoracic and Cardiovascular Surgery, Saga University Medical Hospital, Saga, Japan. ${ }^{3}$ Department of Cardiology, Saga University Medical Hospital, Saga, Japan.

Received: 3 July 2019 Accepted: 26 July 2019

Published online: 05 August 2019

\section{References}

1. Roser MH, Okusa MD. Acute kidney injury associated with cardiac surgery. Clin J Am Soc Nephrol. 2006;1:19-32.

2. Chertow GM, Levy EM, Hammermeister KE, Grover F, Daley J. Independent association between acute renal failure and mortality following cardiac surgery. Am J Med. 1998;104:343-8.

3. Loef BG, Epema AH, Smilde TD, Henning RH, Ebels T, Navis G, et al. Immediate postoperative renal function deterioration in cardiac surgical patients predicts in hospital mortality and long-term survival. J Am Soc Nephrol. 2005;16:195-200.

4. Lok CE, Austin PC, Wang H, Tu JV. Impact of renal insufficiency on short- and long-term outcomes after cardiac surgery. Am Heart J. 2004;148:430-8.

5. Mehta RL, Kellum JA, Shah SV, Molitoris BA, Ronco C, Warnock DG, et al. Acute kidney injury network: report of an initiative to improve outcomes in acute kidney injury. Crit Care. 2007;11:R31.

6. Rihal CS, Textor SC, Grill DE, Berger PB, Ting HH, Best PJ, et al. Incidence and prognostic importance of acute renal failure after percutaneous coronary intervention. Circulation. 2002;105:2259-64.

7. Thiele RH, Isbell JM, Rosner MH. AKI associated with cardiac surgery. Clin J Am Soc Nephrol. 2015;10:500-14.

8. Silva RG, Silva NG, Lucchesi F, Burdmann EA. Prevention of contrastinduced nephropathy by use of bicarbonate solution: preliminary results and literature review. J Bras Nefrol. 2010;32:292-302.

9. Dangs G, lakovou I, Nikolsky E, Aymong ED, Mintz GS, Kipshidze NN, et al. Contrast-induced nephropathy after percutaneous coronary intervention in relation to chronic kidney disease and hemodynamic variables. Am J Cardiol. 2005;95:13-9.

10. Mehran R, Aymong ED, Nikolsky E, Lasic Z, lakovou I, Fahy M, et al. A simple risk score for prediction of contrast-induced nephropathy after percutaneous coronary intervention: development and initial validation. J Am Coll Cardiol. 2004;44:1393-9.

11. Cigarroa RG, Lange RA, Williams RH, Hillis LD. Dosing of contrast material to prevent contrast nephropathy in patients with renal disease. Am J Med. 1989;86:649-52.

12. Freeman RV, O'Donnell M, Share D, Meengs WL, Kline-Rogers E, Clark $V L$, et al. Nephropathy requiring dialysis after percutaneous coronary intervention and the critical role of an adjusted contrast dose. Am J Cardiol. 2002;90:1068-73.

13. Marenzi G, Assanelli E, Campodonico J, Lauri G, Marana I, De Metrio M, et al. Contrast volume during primary percutaneous coronary intervention and subsequent contrast-induced nephropathy and mortality. Ann Intern Med. 2009;150:170-7.

14. Brown JR, Robb JF, Block CA, Schoolwerth AC, Kaplan AV, O'Connor GT, et al. Does safe dosing of iodinated contrast prevent contrast-induced acute kidney injury? Circ Cardiovasc Interv. 2010;3:346-50.

15. Bagur R, Webb JG, Nietlispach F, Dumont E, De Larochellière R, Doyle D, et al. Acute kidney injury following transcatheter aortic valve implantation: predictive factors, prognostic value, and comparison with surgical aortic valve replacement. Eur Heart J. 2010;31:865-74.

16. Nuis RJ, Rodes-Cabau J, Sinning JM, van Garsse L, Kefer J, Bosmans $J$, et al. Blood transfusion and the risk of acute kidney injury after transcatheter aortic valve implantation. Circ Cardiovasc Interv. 2012;5:680-8.

17. Aregger F, Wenaweser P, Hellige GJ, Kadner A, Carrel T, Windecher S, et al. Risk of acute kidney injury in patients with severe aortic valve stenosis undergoing transcatheter valve replacement. Nephrol Dial Transplant. 2009;24:2175-9.

18. Elhmidi Y, Bleiziffer S, Deutsch MA, Krane M, Mazzitelli D, Lange R, et al. Acute kidney injury after transcatheter aortic valve implantation: incidence, predictors and impact on mortality. Arch Cardiovasc Dis. 2014;107:133-9.

19. Sinning JM, Ghanem A, Steinhauser H, Adenauer V, Hammerstingl C, Nickenig $G$, et al. Renal function as predictor of mortality in patients after percutaneous transcatheter aortic valve implantation. JACC Cardiovasc Interv. 2010;3:1141-9.

20. Thomas M, Schymik G, Walther T, Himbert D, Lefèvre T, Treede H, et al. Thirty-day results of the SAPIEN aortic Bioprosthesis European Outcome (SOURCE) Registry: a European registry of transcatheter aortic valve implantation using the Edwards SAPIEN valve. Circulation. 2010;122:62-9.

21. Saia F, Ciuca C, Taglieri N, Marrozzini C, Savini C, Bordoni B, et al. Acute kidney injury following transcatheter aortic valve implantation: incidence, predictors and clinical outcome. Int J Cardiol. 2013;168:1034-40.

22. Elhmidi Y, Bleiziffer S, Piazza N, Hutter A, Opitz A, Hettich I, et al. Incidence and predictors of acute kidney injury in patients undergoing transcatheter aortic valve implantation. Am Heart J. 2011;161:735-9.

23. Alassar A, Roy D, Abdulkareem N, Valencia O, Brecker S, Jahangiri M. Acute kidney injury after transcatheter aortic valve implantation: incidence, risk factors, and prognostic effects. Innovations (Phila). 2012;7:389-93.

24. Nuis RJ, Van Mieghem NM, Tzikas A, Piazza N, Otten AM, Cheng J, et al. Frequency, determinants, and prognostic effects of acute kidney injury and red blood cell transfusion in patients undergoing transcatheter aortic valve implantation. Catheter Cardiovasc Interv. 2011;77:881-9.

25. Barbash IM, Ben-Dor I, Dvir D, Maluenda G, Xue Z, Torguson R, et al. Incidence and predictors of acute kidney injury after transcatheter aortic valve replacement. Am Heart J. 2012;163:1031-6.

26. Khawaja MZ, Thomas M, Joshi A, Asrress KN, Wilson K, Bolter K, et al. The effects of VARC defined acute kidney injury after transcatheter aortic valve implantation (TAVI) using the Edwards bioprosthesis. Eurointervention. 2012;8:563-70.

27. Van Linden A, Kempfert J, Rastan AJ, Holzhey D, Blumenstein J, Schuler $G$, et al. Risk of acute kidney injury after minimally invasive transapical aortic valve implantation in 270 patients. Eur J Cardiothorac Surg. 2011;39:835-42.

28. Konigstein M, Ben-Assa E, Abramowitz Y, Steinvil A, Leshem Rubinow E, Havakuk O, et al. Usefulness of updated Valve Academic Research Consortium-2 criteria for acute kidney injury following transcatheter aortic valve implantation. Am J Cardiol. 2013;112:1807-11. 
29. Goebel N, Baumbach H, Ahad S, Voehringer M, Hill S, Albert M, et al. Transcatheter aortic valve replacement: does kidney function affect outcome? Ann Thorac Surg. 2013;96:507-12.

30. Madershahian N, Scher M, Liakopoulos O, Rahmanian P, Kuhn E, Hellmich $M$, et al. Renal impairment and transapical aortic valve implantation: impact of contrast medium dose on kidney function and survival. Eur J Cardiothorac Surg. 2012:41:1225-32.

31. Maximilian S, Thorsten W. Acute kidney injury after transcatheter aortic valve implantation. J Thorac Dis. 2015:7:1527-35.

32. Kappetein AP, Head SJ, Genereux P, Piazza N, van Mieghem NM, Blackstone $\mathrm{EH}$, et al. Updated standardized endpoint definitions for transcatheter aortic valve implantation: the Valve Academic Research Consortium-2 consensus document. Eur Heart J. 2012;33:2403-18.

33. Jiayang W, Wenyuan Y, Ye Z, Yang Y, Li C, Liu N, et al. Independent risk factors contributing to acute kidney injury according to updated Valve Academic Research Consortium-2 criteria after transcatheter aortic valve implantation: a meta-analysis and meta-regression of 13 studies. J Cardiothorac Vasc Anesth. 2017;31:816-26.

34. Schymik G, Wurth A, Bramlage P, Herbinger T, Heimeshoff M, Pilz L, et al. Long-term results of transapical versus transfemoral TAVI in a real world population of 1000 patients with severe symptomatic aortic stenosis. Circ Cardiovasc Interv. 2015;8:e000761.

35. Biancari F, Rosato S, D’Errigo P, Ranucci M, Onorati F, Barbanti M, et al. Immediate and intermediate outcome after transapical versus transfemoral transcatheter aortic valve replacement. Am J Cardiol. 2016;117:245-51.

36. Thongprayoon C, Cheungpasitporn W, Gillaspie EA, Greason KL, Kashani KB. The risk of acute kidney injury following transapical versus transfemoral transcatheter aortic valve replacement: a systematic review and meta-analysis. Clin Kidney J. 2016;9:560-6.

37. Kumar N, Khera R, Fonarow GC, Bhatt DL. Comparison of outcomes of transfemoral versus transapical approach for transcatheter aortic valve implantation. Am J Cardiol. 2018;122:1520-6.

38. Konigstein M, Ben-Assa E, Banai S, Shacham Y, Ziv-Baran T, Abramowitz $Y$, et al. Periprocedural bleeding, acute kidney injury, and long-term mortality after transcatheter aortic valve implantation. Can J Cardiol. 2015;31:56-62.

39. Keles T, Ayhan H, DurmazT, Cenk S, Aslan NA, Erdoğan KE, et al. Improvement in renal function with transcatheter aortic valve implantation. J Geriatr Cardiol. 2013;10:317-22.

40. Seiffert M, Schnabel R, Conradi L, Diemert P, Schirmer J, Koschyk D, et al. Predictors and outcomes after transcatheter aortic valve implantation using different approaches according to the valve academic research consortium definitions. Catheter Cardiovasc Interv. 2013;82:640-52.

41. Yamamoto M, Hayashida K, Mouillet G, Chevalier B, Meguro K, Watanabe $Y$, et al. Renal function-based contrast dosing predicts acute kidney injury following transcatheter aortic valve implantation. JACC Cardiovasc Interv. 2013:6:479-86.

\section{Publisher's Note}

Springer Nature remains neutral with regard to jurisdictional claims in published maps and institutional affiliations.
Ready to submit your research? Choose BMC and benefit from:

- fast, convenient online submission

- thorough peer review by experienced researchers in your field

- rapid publication on acceptance

- support for research data, including large and complex data types

- gold Open Access which fosters wider collaboration and increased citations

- maximum visibility for your research: over $100 \mathrm{M}$ website views per year

At BMC, research is always in progress.

Learn more biomedcentral.com/submissions 